\title{
The rediscovery of Rhodnius domesticus Neiva \& Pinto, 1923 (Hemiptera: Reduviidae: Triatominae) in the state of Espírito Santo, Brazil
}

\author{
Guilherme Sanches Corrêa-do-Nascimento ${ }^{[1]}$, Danielle de Oliveira Moreira ${ }^{[2]}$, Cleber Galvão ${ }^{[3]}$, \\ Claudiney Biral dos Santos ${ }^{[1]}$, Aloísio Falqueto ${ }^{[1]}$ and Gustavo Rocha Leite ${ }^{[1]}$
}

[1]. Universidade Federal do Espírito Santo, Unidade de Medicina Tropical, Maruípe, Vitória, ES, Brasil.

[2]. Instituto Nacional da Mata Atlântica, Santa Teresa, ES, Brasil.

[3]. Fundação Oswaldo Cruz, Instituto Oswaldo Cruz,

Laboratório Nacional e Internacional de Referência em Taxonomia de Triatomíneos, Rio de Janeiro, RJ, Brasil.

\begin{abstract}
Introduction: Rhodnius domesticus Neiva \& Pinto, 1923 is a rare sylvatic triatomine endemic to the Atlantic Forest, with one known record for Espírito Santo (ES), Brazil from 1969. We present here its rediscovery in ES, 42 years after its first record. Methods: In January 2011, a triatomine specimen was collected from a rural area of the municipality of Santa Teresa, ES. Results: We confirmed this as a new record of $R$. domesticus in the Baixo Caldeirão locality. Conclusions: This finding supports the possibility of a wild population of $R$. domesticus in the mountainous region of the Atlantic forest of ES.
\end{abstract}

Keywords: Insect vectors. Rhodnius. Triatominae. Chagas disease. Animal distribution. Brazil.

Chagas disease, an infection caused by the protozoan parasite Trypanosoma cruzi Chagas, 1909, was originally a sylvatic enzootic infection that began to be a risk when some triatomine vectors became domiciliated ${ }^{1}$. However, predominant sylvatic and less-studied triatomines can invade and sporadically colonize anthropic habitats ${ }^{2}$. As these invasions theoretically start the process of domiciliation, studies on sylvatic triatomine species are important for controlling Chagas disease ${ }^{3,4}$.

Species of the subfamily Triatominae are blood-sucking insects that are vectors of Chagas disease, which is transmitted to humans and other mammals through the feces and urine of infected triatomines, usually immediately after a blood meal. Currently, this group of vectors consists of 151 extant and three fossil species assigned to five tribes ${ }^{5}$. The tribe Rhodniini contains two genera, Rhodnius Stål, 1859 and Psammolestes Bergroth, 19116. Despite their different morphologies and ecological habits, both are mainly

\footnotetext{
Corresponding author: Guilherme Sanches Corrêa-do-Nascimento. e-mail: guisanchescn@gmail.com

(D) https://orcid.org/0000-0001-9279-3017

Received 30 May 2020

Accepted 5 August 2020
}

arboricolous. The genus Rhodnius is well-characterized and can be easily differentiated from other triatomine genera due to the presence of apically inserted antennae and distinct callosities behind the eyes ${ }^{7}$. On the other hand, their species are almost identical ${ }^{8}$.

Rhodnius domesticus is a species that, despite what is suggested by its specific epithet, essentially has sylvatic habits and it occasionally invades human domiciles possibly when attracted by artificial light sources. Researchers have proposed that the species is associated with bromeliads, palms, and marsupial and rodent nests9. However, several of the very few reported records for the species are from domestic and peridomestic areas ${ }^{10}$.

R. domesticus, endemic to the Brazilian Atlantic forest, has already been reported in the Brazilian states of Bahia, ES, Minas Gerais, Paraná, Rio de Janeiro, São Paulo, and Santa Catarina ${ }^{6}$. Further knowledge about the natural habits of $R$. domesticus is required to understand species distribution. Rhodnius zeledoni Jurberg, Rocha \& Galvão, 2009, which seems to be identical to $R$. domesticus, was described based on only one very damaged specimen found in the state of Sergipe, Brazil, a region possibly included within the distribution of $R$. domesticus. Therefore, the examination of further material is essential to confirm whether R. zeledoni is a valid species ${ }^{6}$. 
To date, ES has a single known occurrence record of $R$. domesticus from 1969 in the municipality of Alfredo Chaves ${ }^{11}$. Since that first and unique record, the species was not found again in the state. We present here the rediscovery of $R$. domesticus in the state of ES, 42 years after its first and single record.

In January 2011, a local person captured a triatomine specimen in a chicken coop next to his residence in a rural area of the locality of Baixo Caldeirão, municipality of Santa Teresa, ES $\left(19.9138^{\circ} \mathrm{S}\right.$ and $40.7517^{\circ} \mathrm{W}$ ) (Figure 1). We investigated the site of the record and its surrounding areas, but we could not find another specimen. Since there was no evidence of colonies in the domestic and peridomestic areas, it seemed likely that the insect was dispersed from adjacent forests.

We identified the collected specimen as a female of $R$. domesticus in the Laboratory of Entomology of the Espírito Santo State Department of Health. Specialists of the National and International Laboratory of Taxonomy of Triatominae of the Oswaldo Cruz Institute, Fiocruz (Rio de Janeiro, Brazil) confirmed the taxonomic identity of the species. Because the insect was dead and dry, we could not test for T. cruzi infection.

The collected specimen presented a length of $15 \mathrm{~mm}$, a maximum width of the pronotum of $3.64 \mathrm{~mm}$, and a maximum width of the abdomen of $5.92 \mathrm{~mm}$. The length of the head was approximately 2.5 times the width across the eyes (1:0.43), and it was slightly longer than the pronotum (1:0.96). The anteocular region was three times longer than the postocular region (1:0.33). The ratio of the width of the eye to the synthlipsis was 1:1.43 (Figure 2). The specimens presented compatible ratios but with slightly smaller measurements than those provided by Lent and Wygodzinsky ${ }^{7}$ and Neiva and Pinto $^{8}$ in the original species description; in a general way, the features were consistent with those provided by them. A short $R$. domesticus female, 15.5 -mm-long, was also recently collected in Minas Gerais ${ }^{10}$.

The area where the specimen was collected, the mountainous region of ES, is occupied by small familiar crops and forest fragments. It has an irregular terrain with an approximate elevation of $500 \mathrm{~m}$ above sea level, characterized by mild temperatures with an average annual temperature of $21^{\circ} \mathrm{C}$. The locality is in a transitional zone between tropical rainy and dry climates, with an approximate annual rainfall of 1,200 $\mathrm{mm}^{12}$. The site was characterized as a rocky area (Figure 1).

Surprisingly, there was a gap of 42 years between the two known $R$. domesticus records in ES. This made us reckon that either the 1969 record was an error, or that the species no longer existed in that region. For example, during 10 years of fieldwork, between 1996 and 2005, collectors captured almost 4,000 triatomines in ES, and none of them was $R$. domesticus. Several captures occurred in Alfredo Chaves and Santa Teresa, the only two municipalities in ES where $R$. domesticus is now known ${ }^{13}$. This may indicate that $R$. domesticus is a specialist species with small and restricted populations because of its biological and ecological characteristics,

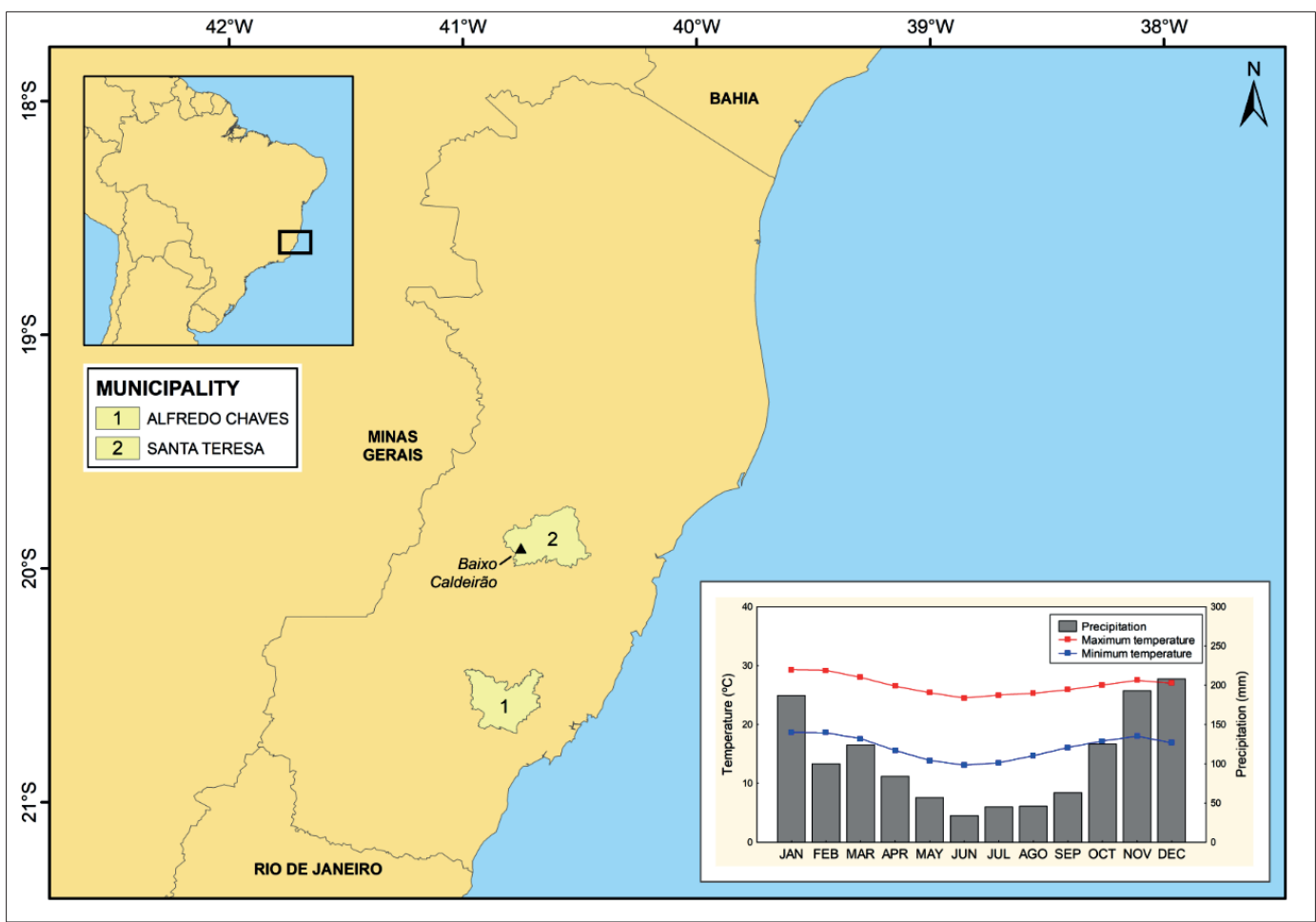

FIGURE 1: Map of the state of Espírito Santo, Brazil, showing [1] the municipality of Alfredo Chaves, where R. domesticus was found for the first time in 1969, and [2] the locality of Baixo Caldeirão, municipality of Santa Teresa, where we report its rediscovery 42 years after its unique register in ES. The monthly maximum and minimum temperatures and precipitation for the locality are presented in the map graph inside ${ }^{12}$. 


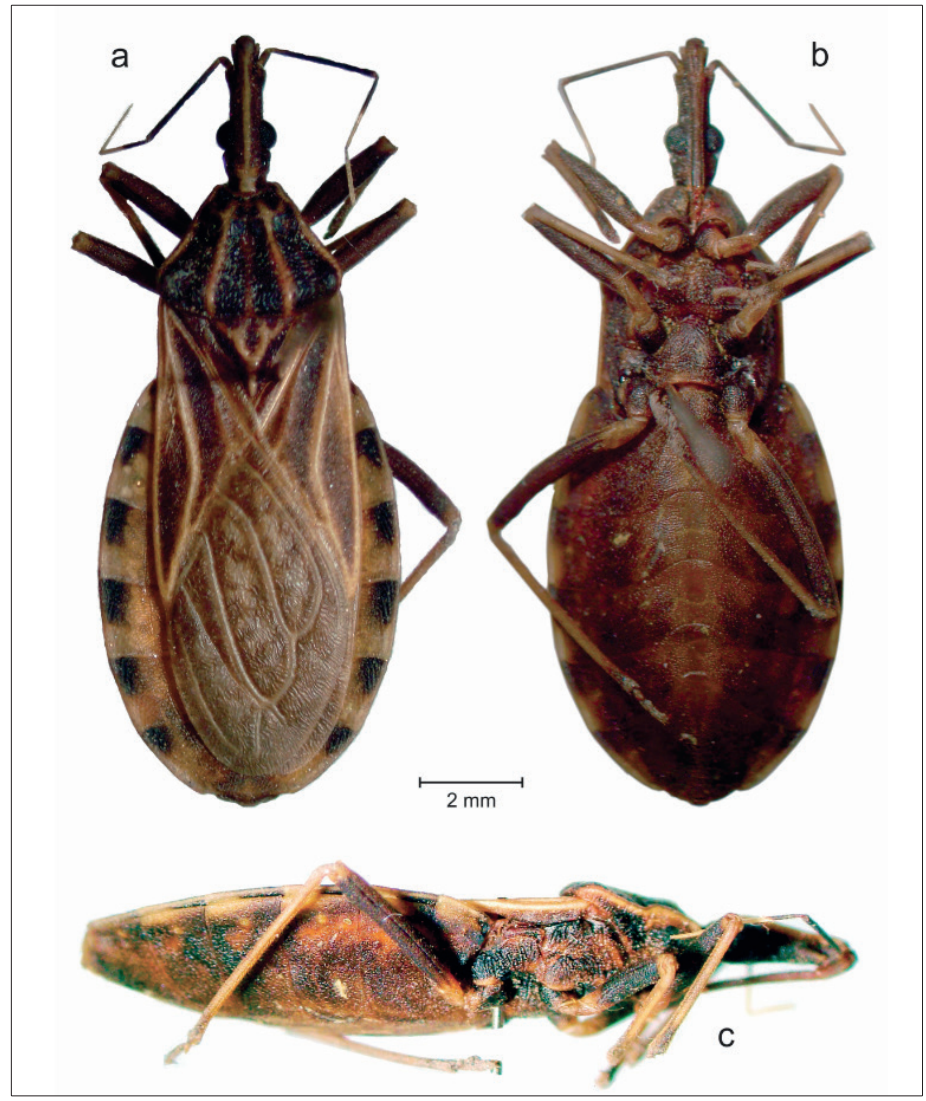

FIGURE 2: Original photographs of the Rhodnius domesticus female specimen collected in the locality of Baixo Caldeirão (19.9138 $\mathrm{S}$ and $\left.40.7517^{\circ} \mathrm{W}\right)$, Santa Teresa, Espírito Santo, Brazil, in January 2011, showing it in (a) dorsal, (b) ventral, and (c) lateral view.

such as its occurrence in habitats formed by epiphytic bromeliads in association with specific small mammal nests ${ }^{14}$. In addition, artificial light may not attract it with the same intensity at which it attracts other triatomine species ${ }^{13}$.

Both the known occurrences of $R$. domesticus, even though collected over 40 years apart, are located in relatively close areas, suggesting a wild population in ES. The confirmation of the species occurrence is important for two main reasons: ES may comprise areas with one of the highest $T$. cruzi infection rates of triatomines ever recorded $^{15}$, and R. domesticus, distributed largely in the Atlantic Forest, is the only species of the monophyletic Rhodniini tribe that occurs in $\mathrm{ES}^{6}$. Clarifying the geographic distribution of $R$. domesticus helps to understand the epidemiological and sylvatic cycles of Chagas disease as well as the evolutionary and endemism patterns in the Rhodniini group.

\section{AUTHORS' CONTRIBUTION}

GSCN: Analysis and investigation of data, Funding acquisition, Drafting original manuscript, Review and editing manuscript; DOM: Drafting original manuscript, Review and editing manuscript; CG: Study conceptualization, Data curation, Analysis and investigation of data, Resource provider, Review and editing manuscript; CBS: Study conceptualization, Data curation, Analysis and investigation of data, Resource provider; AF: Study conceptualization, Analysis and investigation of data, Resource provider GRL: Study conceptualization, Analysis and investigation of data, Funding acquisition, Resource provider, Drafting original manuscript, Review and editing manuscript, Project supervision.

\section{FINANCIAL SUPPORT}

Fundação de Amparo à Pesquisa e Inovação do Espírito Santo (FAPES).

\section{CONFLICT OF INTEREST}

The authors declare that there is no conflict of interest.

\section{REFERENCES}

1. Guhl F, Jaramillo C, Vallejo GA, A-Arroyo FC, Aufderheide A. Chagas Disease and Human Migration. Mem Inst Oswaldo Cruz. 2000;95(4):553-5.

2. dos Santos CB, Ferreira AL, Leite GR, Ferreira GEM, Rodrigues AAF, Falqueto A. Peridomiciliary colonies of Triatoma vitticeps (Stal, 1859) (Hemiptera, Reduviidae, Triatominae) infected with Trypanosoma cruzi in rural areas of the state of Espírito Santo, Brazil. Mem Inst Oswaldo Cruz. 2005;100(5):471-3.

3. Noireau F, Abad-Franch F, Valente SAS, Dias-Lima A, Lopes CM, Cunha V, et al. Trapping triatominae in silvatic habitats. Mem Inst Oswaldo Cruz. 2002;97(1):61-3.

4. Schofield CJ, Diotaiuti L, Dujardin JP. The Process of Domestication in Triatominae. Mem Inst Oswaldo Cruz. 1999;94(Suppl 1):375-8.

5. Peixoto SR, Rocha D da S, Dale C, Galvão C. Panstrongylus geniculatus (Latreille, 1811) (Hemiptera, Reduviidae, Triatominae): first record on Ilha Grande, Rio de Janeiro, Brazil. Check List 7AD;2020;16(2):391-4.

6. Galvão C, Gurgel-Gonçalves R. Vetores conhecidos no Brasil. In: Galvão C, editor. Vetores da doença Chagas no Brasil. 1 ed. Curitiba: Sociedade Brasileira de Zoologia; 2014. p. 88-170.

7. Lent H, Wygodzinsky P. Revision of the Triatominae (Hemiptera, Reduviidae), and their significance as vectors of Chagas' disease. Bull Am Museum Nat Hist. 1979;163:127-520.

8. Neiva A, Pinto C. Estado actual dos conhecimentos sobre o gênero Rhodnius Stal, com a descrição de uma nova espécie. Bras Med. 1923;37:20-4.

9. Lent H. Transmissores da moléstia de Chagas no estado do Rio de Janeiro. Rev Flum Med. 1942;7:151-62.

10. Ferreira RA, Silva JD, Machado De Faria TC, Lage DL, Barbosa SE, Diotaiuti LG. Primeiro encontro de Rhodnius domesticus Neiva \& Pinto, 1923 (Hemiptera: reduvidae) no município de Açucena, Minas Gerais, Brasil. Rev Patol Trop. 2014;43(3):369-75.

11. Santos UM, Pinto AFS, Almeida AZ, Zanganelli FL, Carrancho P V, Netto AN. Doença de Chagas no estado do Espírito Santo - III - Vetores do tripanosoma. 1969. Rev Soc Bras Med Trop. 1969;3:51-2.

12. Fick SE, Hijmans RJ. WorldClim 2: new 1-km spatial resolution climate surfaces for global land areas. Int J Climatol. 2017;37(12):4302-15.

13. Leite GR, dos Santos CB, Falqueto A. Influence of the landscape on dispersal of sylvatic triatomines to anthropic habitats in the Atlantic Forest. J Biogeogr. 2011;38:651-63.

14. Leal H, Ferreira-Neto JA, Martins CM. Dados ecológicos sobre os triatomíneos silvestres na Ilha de Santa Catarina. Rev Inst Med Trop Sao Paulo. 1961;3:213-20.

15. dos Santos CB, Leite GR, Melim Ferreira GE, Ferreira AL. Infecção natural de Triatoma vitticeps (Stal, 1859) por flagelados morfologicamente semelhantes a Trypanosoma cruzi (Chagas, 1909) no Estado do Espírito Santo. Rev Soc Bras Med Trop. 2006;39(1):89-91. 